\title{
Removal of methylene blue from aqueous solution by ozone microbubbles
}

\author{
Ola A. Nashmi ${ }^{1}$, Nada N. Abdulrazzaq ${ }^{2}$ and Ahmed A. Mohammed ${ }^{3}$ \\ 'Department of Environmental Engineering, University of Baghdad, Baghdad, Iraq, olawissam86@gmail.com \\ ${ }^{2}$ Department of Chemical Engineering, University of Baghdad, Baghdad, Iraq, nnabdulrazzaq@coeng.uobaghdad.edu.iq \\ ${ }^{3}$ Department of Environmental Engineering, University of Baghdad, Baghdad, Iraq, ahmed.abedm@yahoo.com \\ *Corresponding author: Ola A. Nashmi, olawissam86@gmail.com
}

Published online: 30 September 2020

Abstract - In this work, ozone microbubbles (OMBs) technique was used to remove methylene blue dye (MB) from water in a semi- batch reactor. The removal efficiency of methylene blue dye were investigated under various reaction conditions such as effect of initial solution $\mathrm{pH}$, ozone generation rate, initial methylene blue dye concentration and determination of mass transfer coefficient. The removal of methylene blue by Ozonation microbubbles were very high at the acidic media and upon increasing ozone generation rate from 0.498 to $0.83 \mathrm{mg} \mathrm{s}^{-1}$, the removal efficiency dramatically increased from 8 to $98 \%$.The overall rate of the oxidation reaction fitted well a second order kinetic model. The results demonstrated that ozone microbubbles were effective in terms of the elimination of methylene blue concentration and its complete mineralization.

Keywords- Methylene Blue, Ozone Microbubble, Removal Rate.

\section{Introduction}

Industrial wastewaters are becoming more and more complex and that was owing to the attendance of emerging impurities. Water is essentially contaminated by the wastes that discharge from several industrial performances. The random discharge of these effluents into the environment without a proper remediation can cause major environmental problems. Among these contaminants, organic pollutants such as dyes, are the most important ones as they pose serious threat to the ecosystem [13]. Dyes are toxic contaminants in water and wastewater which causes remarkable threat to the environment if their concentration exceeds the acceptable limits[23]. They can remain in the environment for a long period of time if they are not addressed with an adequate treatment [20]. In fact, the direct dye discharge that containing effluents into water is unfavorable, and that's not related to their color only, but also because various of these released dyes and their breakdown products be toxic, mutagenic or carcinogenic to life forms mainly because of the presence of carcinogens, such as naphthalene, benzidine and other aromatic components [2]. Over the years, numerous technologies have been investigated for treating dyed wastewater. These include chemical, physical and biological methods. Chemical oxidation is the generally used technique for the elimination of organics contaminated wastewater. This technique is more efficient than other methods and can be used for the treatment of some persistent pollutants. The organic contaminants can efficiently break down into smaller compounds or even convert into carbon dioxide and water by oxidants [21]. Ozonation process is a typical example of the chemical oxidation method in which the reaction rate is impacted by both the reaction kinetics and mass transfer [5]. Ozone is a strong oxidation and disinfection agent that has been widely applied in the field of water and wastewater treatment [29]. However, its use is limited by the conventional high energy consumption. In conventional reactors, dosing of ozone is achieved by inserting a gas jet into the water stream. The mass transfer is improved by turbulent flow of the gas stream, however this procedure is troubled by low mass transfer rates [19]. In addition, substantial amount of ozone is lost, which resulted in a considerable loss of energy. So that, a better gas-liquid system is required that can achieve quick oxidation of the organic compounds, and also mitigate the ozone loss. The rate of ozone mass transfer can be greatly enhanced by microbubble dispersal [19]. Microbubble technology has been widely applied for improving ozone-based oxidation processes for wastewater treatment owing to their important physicochemical properties, such as: low terminal velocity through water, large gas-liquid interfacial area, 
and electrically charged gas-liquid interface [18]. These properties are of highly importance and effective in the enhancement of the rate of transfer of ozone into water and the generation of hydroxyl radical $\left(\mathrm{OH}^{-}\right)$which is a strong oxidant [16]. Hence, ozone microbubbles may be an efficient alternative option for the complete elimination of MB from water.

The aim of the present work is to investigate the removal efficiency of Methylene Blue dye (MB), as an important basic dye, by ozone microbubbles using a commercial microbubble generator (microbubble diffuser). This work was unrtaken to investigate the capability of ozone microbubbles in the rate treatment of wastewater contaminated with methylene blue dyes ( MB). In addition the effect of various operating conditions on the degradation of MB such as the initial concentration of $\mathrm{MB}$, the $\mathrm{pH}$ of the reaction medium and the ozone generation rate were investigated.

\section{Mechanisim of Ozonation}

The presence of dyes is a major threat to the environment, and that owes to their property which is physical (color) and chemical property (toxicity). The diversity and intensity of dyes color is caused a potential problem when they are discharged into water streams. Generally, the color must be decolorized previous to the subsequently step of the treatment[24]. Moreover, numerous dyes are toxic and may possibly a reason for genetic mutations. As well, the natural environment does not recognize them and does not degrade their toxicity easily due to their synthetic origin [7]. Oxidation of dye particles in general, includes the oxidant assault on the sulfinic group (methylene blue) or assault on the binary bond between $\mathrm{N}$ molecules (azo dyes). Despite the fact that the break of dye atoms is adequate to wipe out undesirable shading, different mixes are delivered during oxidation, which is once in a while hard to change over [9]. By far, color degradation by ozonation process is a promising choice as it provides several advantages. It has absence of chemical sludge residue afterward the process, has the capability to degrade both organic pollutant and color in single step as well as having less danger than conventional methods because no stock of any chemical is needed and the residual ozone can be easily decomposed to oxygen in water, [4]. The direct and indirect reactions of ozonation process depend significantly on the $\mathrm{pH}$ of the solution. At acidic solution $\mathrm{pH}$, the rate of ozone decomposition was very slow and negligible; therefore, as indicated by the responses given below [30], atomic ozone responds straightforwardly with organics or inorganics and oxidizes them:

$$
\begin{aligned}
& \mathrm{O}_{3}+\text { Organics } \rightarrow \text { By products }+\mathrm{H}_{2} \mathrm{O}+\mathrm{CO}_{2} \\
& \mathrm{O}_{3}+\text { Organics } \rightarrow \mathrm{HO}+\text { By products }+\mathrm{H}_{2} \mathrm{O}+ \\
& \mathrm{CO}_{2}
\end{aligned}
$$

When the dye molecules were oxidized by ozone, first of all it assaults the dye chromophore group as well as break down its construction [25]. In accordance with the literature, molecular ozone reacts with organics such as phenols, aromatic compounds and amines easily; however, alternatively, the reaction of aldehydes, carboxylic acids and alcohols occurs more slowly with ozone, [11]. Observably, it is able to conclude that the direct and indirect ozone reactions are selective and depends on the target compound. When $\mathrm{pH}$ exceeds 7 , Ozone decomposition starts to occur by the reaction of hydroxyl ions (OH-) with $\mathrm{O} 3$. Ozone decomposition provides the formation of hydroxyl radicals and enhances the hydroxyl radical reactions with organics [22]. Chu et al. (1999) [4], have stated that molecular ozone reacts with organics at acidic $\mathrm{pH}$, however, at $\mathrm{pH}$ values more than 7 , the indirect reactions between hydroxyl radicals and organics take place because of the high rate of ozone decomposition.

Staehelin et al. (1985) [28] suggested the potential decomposition reaction of ozone as follows:

$\mathrm{O}_{3}+\mathrm{OH}^{-} \rightarrow \mathrm{HO}_{2}+{ }^{-} \mathrm{O}_{2}$.

After the decomposition of ozone, the following reactions occur in aqueous phase:

$$
\begin{aligned}
& \mathrm{O}_{2}^{-}+\mathrm{O}_{3} \rightarrow-\mathrm{O}_{3}+\mathrm{O}_{2} \\
& \mathrm{O}_{3}^{-}+\mathrm{H}+\rightarrow \mathrm{HO} \cdot+3 \mathrm{HO} \cdot+\mathrm{O}_{2} \\
& \mathrm{O}_{3}+\mathrm{HO} \cdot \rightarrow \mathrm{HO}_{2} \cdot+\mathrm{O} \\
& \text { Organics }+\left(\mathrm{HO} \cdot, \mathrm{O}_{2}^{-}, \mathrm{O}_{3}^{-}\right) \rightarrow \text { By products }+ \\
& \mathrm{CO}_{2}+\mathrm{H}_{2} \mathrm{O}
\end{aligned}
$$

Therefore, both direct and indirect oxidation by ozone and hydroxyl radicals is important in the ozonation process for the removal of dye, TOC and COD.

\section{Experimental section}

\subsection{Materials}

The chemicals used in the current work were methylene blue dye MB (, $(0.1 \mathrm{M})$ sodium hydroxide and $(0.1 \mathrm{M})$ hydrochloric acid. All chemicals were of high purity and analytical grade. Stock solutions were prepared and diluted as the requirements. The chemical structure and properties of MB is shown in Figure 1.

$\begin{array}{ll}\text { Chemical structure } & \begin{array}{l}\text { Basic } \\ \text { At room temperature it } \\ \text { appears as a solid, dark green } \\ \text { powder that yields a blue } \\ \text { solution when dissolved in } \\ \text { water }\end{array} \\ & \begin{array}{l}\text { Odorless } \\ \text { Odor }\end{array} \\ \text { Solubility } & 3.55 \% \\ \text { Physical state at } 25^{\circ} \mathrm{C} & \text { Solid } \\ \text { Chemical formula } & \mathrm{C}_{16} \mathrm{H}_{15} \mathrm{~N}_{3} \mathrm{ClS} \\ \text { Molecular mass } & 319.85 \\ \text { (g/mol) } & \end{array}$

Figure 1: Methylene blue structure 


\subsection{Experimental methods}

The bench scale of ozone microbubble schematic diagram unit is shown in Figure 2. The setup comprises a column reactor, an oxygen source, an ozone generator (Shanghai ENALY M\&E; model: OZX05K), and a gas distribution system (i.e. diffuser) (A $\mathrm{CO}_{2}$ Bazooka Diffuser) to generate microbubbles. As illustrated in the figure, Oxygen with high-purity was fed to a laboratory ozone generator in which oxygen was converted to ozone by the corona-discharge method. The ozone generation rates that applied in this work were studied in the range of 0.498 $0.83 \mathrm{mg} \mathrm{s}^{-1}$. Oxygen and ozone gas mixture coming out of the ozone generator was then entered a flow meter to measure its flow rate before entering the diffusers which located at the base of the column reactor where the microbubbles were generated. In the microbubble ozone generator, the dissolution of gas in water was attained by applying an oxygen flow rate of $1 \mathrm{~L} / \mathrm{min}$, so microbubbles were continuously generated by the release of pressure. All experiments were performed at room temperature $\left(25 \pm 1^{\circ} \mathrm{C}\right)$, , the initial concentration of $\mathrm{MB}$ in the aqueous solutions was varied in the range of $5-25$ $\mathrm{ppm}$, the $\mathrm{pH}$ of the medium was maintained by using $0.1 \mathrm{M} \mathrm{HCl}$ and $0.1 \mathrm{M} \mathrm{NaOH}$ solutions. The samples from the reactor were collected initially every $60 \mathrm{~s}$ and then after $5 \mathrm{~min}$ they were taken every $300 \mathrm{~s}$ to measure their concentrations.

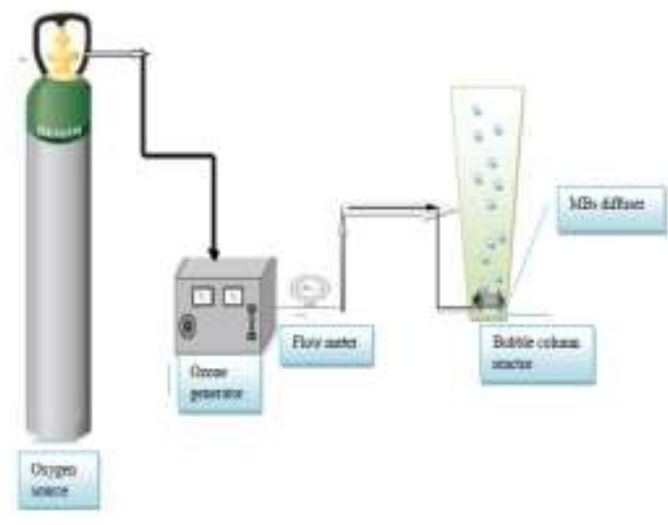

Figure 2: Schematic diagram of the experimental set-up.

\subsection{Analytical method}

All aqueous solutions $\mathrm{pH}$ was measured by the use of a $\mathrm{pH}$ meter (ISOLAB.). Quantitative analysis of the MB dye concentration was made by an ultraviolet UV-visible spectrophotometer (Model: Cary-100 conc., Varian, USA). The wavelength of MB dye was detected at 665 $\mathrm{nm}$. The analysis were repeated at least three times

\section{Results and discussion}

\subsection{De-colorization of MB using ozone microbubbles}

The UV spectrum of MB was determined at $665 \mathrm{~nm}$ as shown in Figure 3. The absorbance as well as the spectrum was rapidly changed with time owing to the fast de-colorization of the solution and the formation of the intermediates. It was observed that more than $90 \%$ of the dye was removed within $15 \mathrm{~min}$ of the ozonation time. The fast decrease in absorbance of $\mathrm{MB}$ from the maximum peak (i.e. $665 \mathrm{~nm}$ ) indicates the quick decomposition of the dye. The strong oxidizing power of ozone as well as the much higher surface contact area available by microbubbles for the same volumetric flow rate, were effective in the fast degradation of $\mathrm{MB}$ from the aqueous solution. About $99 \%$ of $\mathrm{MB}$ was oxidized in $20 \mathrm{~min}$ and that agree with what was obtained by previous studies [12].

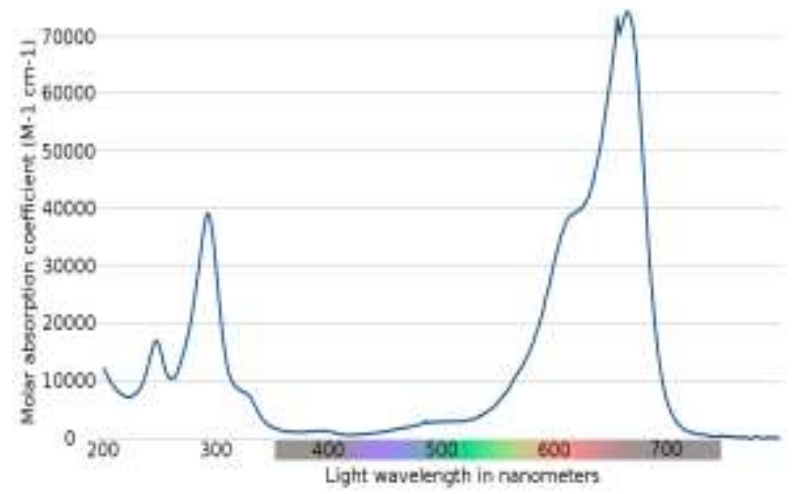

Figure 3: Absorption spectrum of methylene blue (MB)

The rapid de-colorization of MB was also visible within 10 min for all the applied MB concentration which range between 5-25 mg/L. The spectral band changed (after $\sim 5$ min) due to the destruction of the structure of MB by ozone as shown in Figure 4.

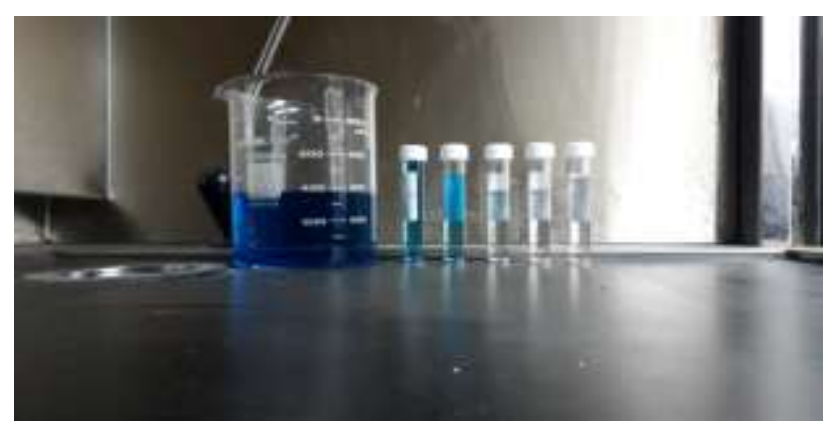

Figure 4: MB samples before and after $20 \mathrm{~min}$ of Ozonation by microbubbles (MB concentration $=25 \mathrm{mg} / \mathrm{l}$, $\mathrm{pH}=3.7$ at room temperature).

\subsection{Effect of the initial concentration of $M B$}

Dye concentrations in water and wastewater change over a wide range. Therefore, it is essential to study the effect of the concentration of $\mathrm{MB}$ on its degradation rate by ozone microbubbles. Experiments were carried out using 
prepared model wastewater solutions with different concentration of $\mathrm{MB}(5,10,15,20$, and 25ppm) at room temperature. The $\mathrm{pH}$ of the solution and the ozone generation rate were kept constant during these experiments at 3.7 and $0.83 \mathrm{mg} / \mathrm{s}$ respectively and the results are presented in Figure 5.

It can be seen from the results that the concentration profiles followed an alike trend for all concentrations of MB applied in the current study. Upon increasing the initial concentration of $\mathrm{MB}$ from 5ppm to $25 \mathrm{ppm}$, the removal efficiency increased from about $95 \%$ to $98 \%$ within $20 \mathrm{~min}$ of ozonation time, indicating that more MB is oxidized by ozone at higher initial concentration. This can be understood by considering that the reaction follows second-order kinetics (first-order with respect to both MB and ozonation). Therefore, the rate of reaction increased with increasing the concentration of $\mathrm{MB}$ and this is accepted with other previous work [12].

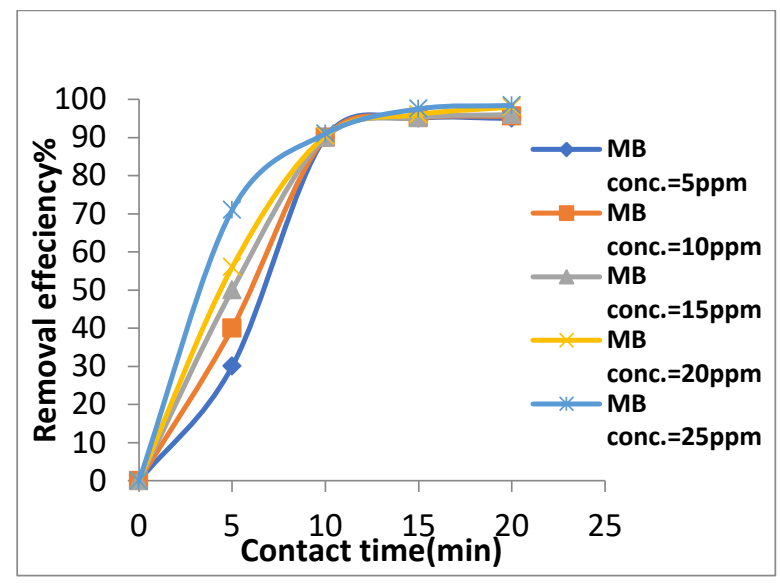

Figure 5: Effect of the initial concentration $\mathrm{MB}$ on the removal efficiency $(\mathrm{pH}=3.7$, ozone generation rate $=0.83 \mathrm{mg} / \mathrm{sec})$.

\subsection{Effect of the initial pH of the feed solution}

It is important to investigate the effect of the solution $\mathrm{pH}$ on the oxidation of methylene blue (MB), since $\mathrm{pH}$ of the aqueous medium controls both the mechanism and the ozonation process rate [1,5]. The ions present in the ozonation system (i.e. $\mathrm{H}^{+}$or $\mathrm{OH}^{-}$) may promote the generation of free radicals which play a vital role in the oxidation of contaminants. The ozone decomposition mechanisms in alkaline and acidic conditions have been proposed previously by several researchers and summarized in the work of Khuntia et al., 2015[18].

The time dependence of the effect of $\mathrm{pH}$ on the oxidation of MB for the current work is shown in Figure 6. The experiments were accomplished at an ozone generation rate of $0.83 \mathrm{mg} / \mathrm{s}$ and an initial $\mathrm{MB}$ concentration of $15 \mathrm{ppm}$. The $\mathrm{pH}$ of the solution was varied from 3.7 to 9.5 to consider both the acidic and alkaline regions. It can be noticed from the results that the acidic medium, (i.e. $\mathrm{pH}$ 3.7) was more suitable for the oxidation of $\mathrm{MB}$ by ozone microbubbles, however with increasing the $\mathrm{pH}$, the removal of $\mathrm{MB}$ decreased significantly. For $20 \mathrm{~min}$ ozonation time, the removals of $\mathrm{MB}$ were $95 \%$ and $20 \%$ at $\mathrm{pH} 3.7$ and 7.1, respectively. More increase in the $\mathrm{pH}$ had a significant influence on the MB removal rate. Thus, it is apparent that the concentration of $\mathrm{OH}-$, which favored the indirect reaction, increased with increasing $\mathrm{pH}$ [11]. In fact, Ozone reacts with organic compounds through a direct attack to the molecule and through free radicals attacks. These radicals, especially hydroxyl radicals, are generated from the ozone decomposition in aqueous solutions. However, the constant stoichiometry obtained with $\mathrm{pH}$ seems to indicate that in the present case, the reaction mainly occurs via the direct attack at low $\mathrm{pH}$ (i.e. $\mathrm{pH} 3.7$ ) and this agree with the previous findings of Grabowsk et al. (2007)[12].

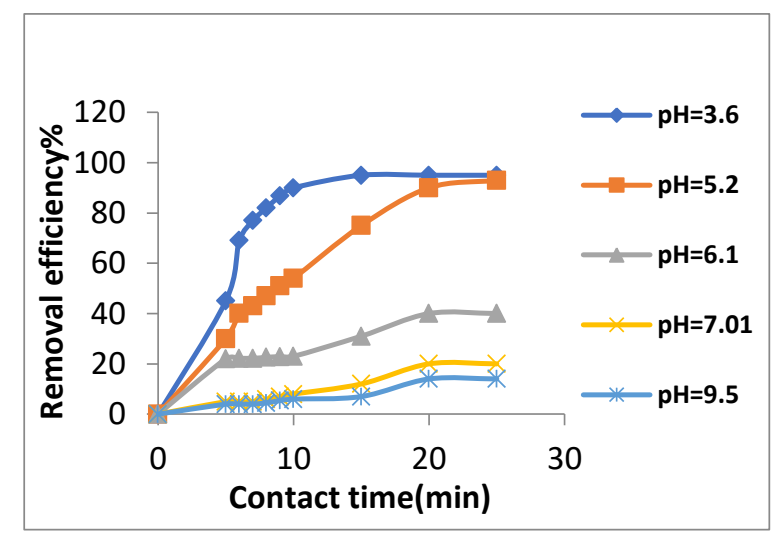

Figure 6: The effect of $\mathrm{pH}$ with time on the removal efficiency of $\mathrm{MB}\left(\mathrm{T}=25^{\circ} \mathrm{C}, \mathrm{MB}\right.$ concentration $=15 \mathrm{mg} / \mathrm{l}$, ozone generation rate $=0.83 \mathrm{mg} / \mathrm{sec})$.

The solution $\mathrm{pH}$ profile with different initial $\mathrm{pH}$ values was also investigated and the results are plotted in Figure 7. From this figure it can be seen that the extent of $\mathrm{pH}$ of the solution was strongly decreased with time for all initial $\mathrm{pH}$ solutions considered in this study. This is expected due to the creation of organic acid intermediates during the oxidation of $\mathrm{MB}$ which dropped the $\mathrm{pH}$ of the medium [12].

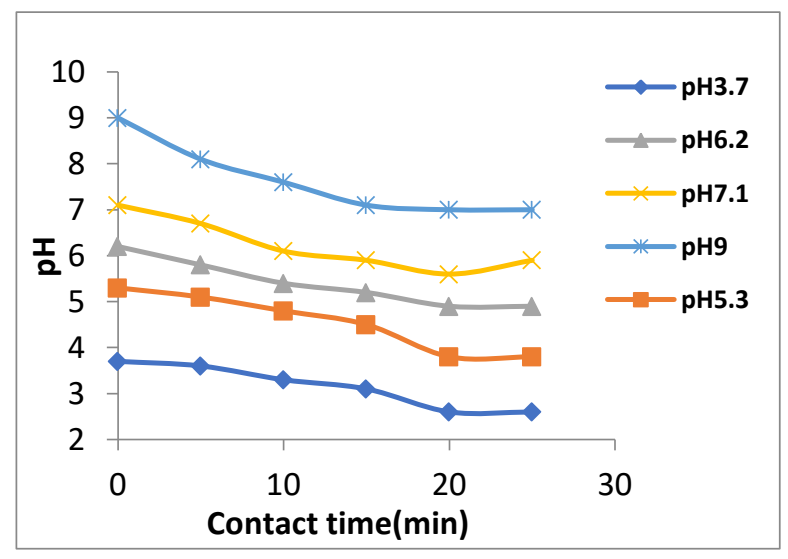

Figure 7: Change of $\mathrm{pH}$ solution with time $\left(\mathrm{T}=25^{\circ} \mathrm{C}, \mathrm{MB}\right.$ concentration $=15 \mathrm{mg} / 1$, ozone generation rate $=0.83$ $\mathrm{mg} / \mathrm{sec})$. 


\subsection{Effect of the ozone concentration:}

Since, the concentration of ozone in the aqueous phase has a great influence on the MB oxidation rate, the next series of experiments were focused on studying its effect on the degradation of MB with ozone microbubbles. In the present study, OMBs experiments were investigated with different ozone generation rates ranging from 0.498 to $0.83 \mathrm{mg} / \mathrm{s}$. The experimental data are plotted in Figure .8 which shows that, when the Ozonation rate increased, the MB removal rate increased. This is expected because increasing ozone concentration in the aqueous phase enhances the direct reaction of ozone with MB and causes to increase the rate of reaction. In addition, increasing the ozone generation rate causes an increase in the partial pressure of ozone in the gas mixture unconfined from the ozonator and these results in an augmentation in the ozone concentration in the aqueous phase, as predicted by Henry's law.

From the data in Figure 8., it can be clearly seen that raising generation rate of ozone from 0.498 to $0.83 \mathrm{mg} / \mathrm{s}$ significantly enhanced the removal rate of MB from $37 \%$ to $98 \%$ within $20 \mathrm{~min}$ of ozonation time. Though, much longer time of ozonation was needed to attain similar removal level when the ozone generation rate was 0.581 $\mathrm{mg} / \mathrm{s}$. Also, it was found that increasing the ozone generation rate further (i.e. beyond $0.83 \mathrm{mg} / \mathrm{s}$ ) had a small effect on the oxidation of MB.

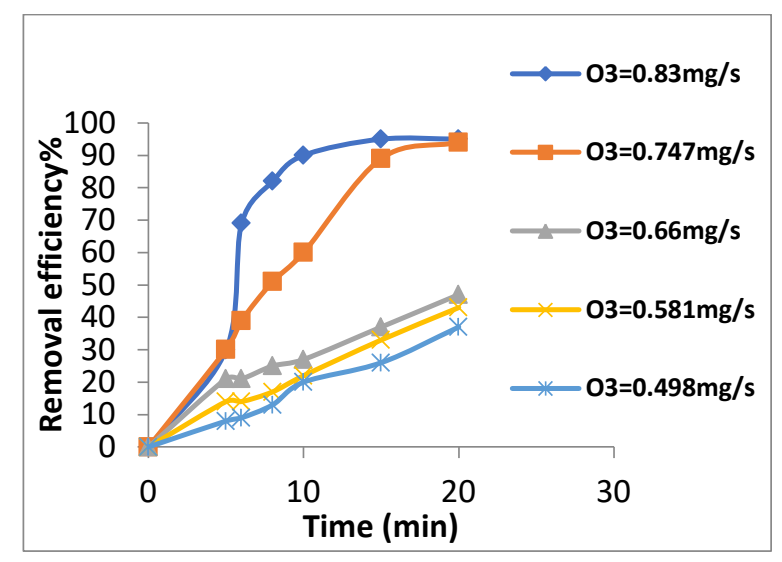

Figure 8: Effect of the ozonation rate on MB removal efficiency $(\mathrm{pH}=3.7, \mathrm{MB}$ concentration=15mg/l).

The change in the $\mathrm{pH}$ solution at different Ozonation rates with time was also studied at different initial $\mathrm{pH}$ values and the results are plotted in Figures [9-13]. From the results presented in these figures, it is evident that with increasing Ozonation rate, the drop in the solution $\mathrm{pH}$ increased with time and this is due to the increase in the transfer of ozone from gas phase to liquid phase [12] which leads, in turn, to increase the decolorization rate and decrease the $\mathrm{pH}$ solution through time as observed in Figure 9.

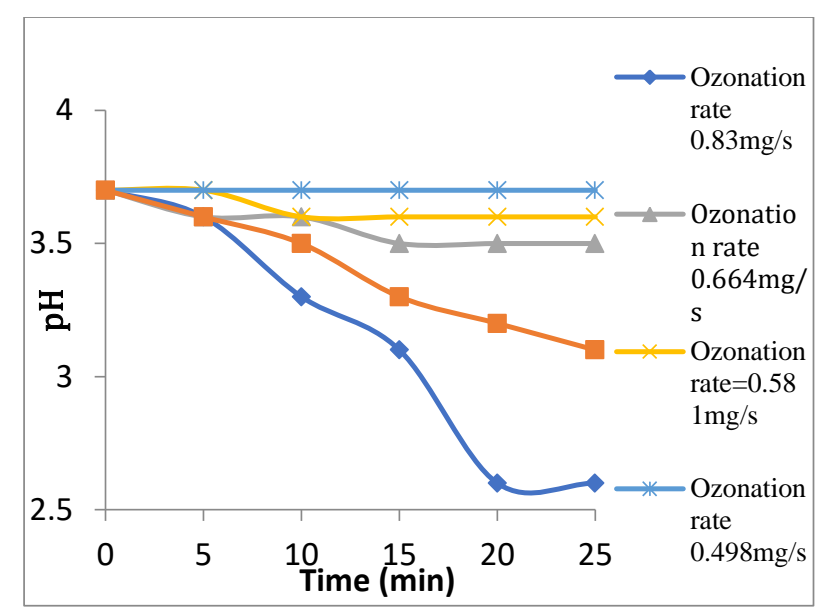

Figure 9: Variation of $\mathrm{pH}$ with Ozonation rate at different time intervals ( $\mathrm{MB}$ concentration $=15 \mathrm{mg} / 1, \mathrm{pH}=$ 3.7).

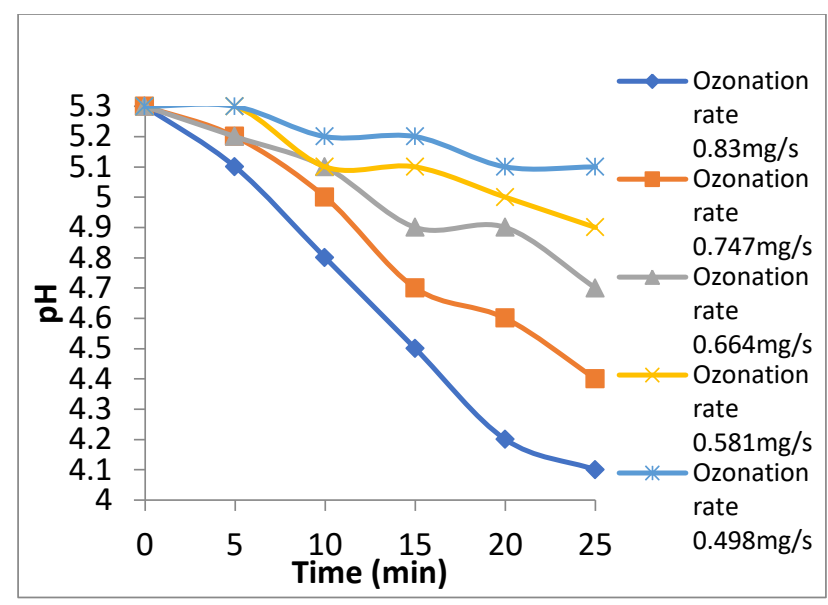

Figure 10: Variation of $\mathrm{pH}$ with Ozonation rate at different time intervals $(\mathrm{MB}$ concentration $=15 \mathrm{mg} / \mathrm{l}, \mathrm{pH}=$ 5.3).

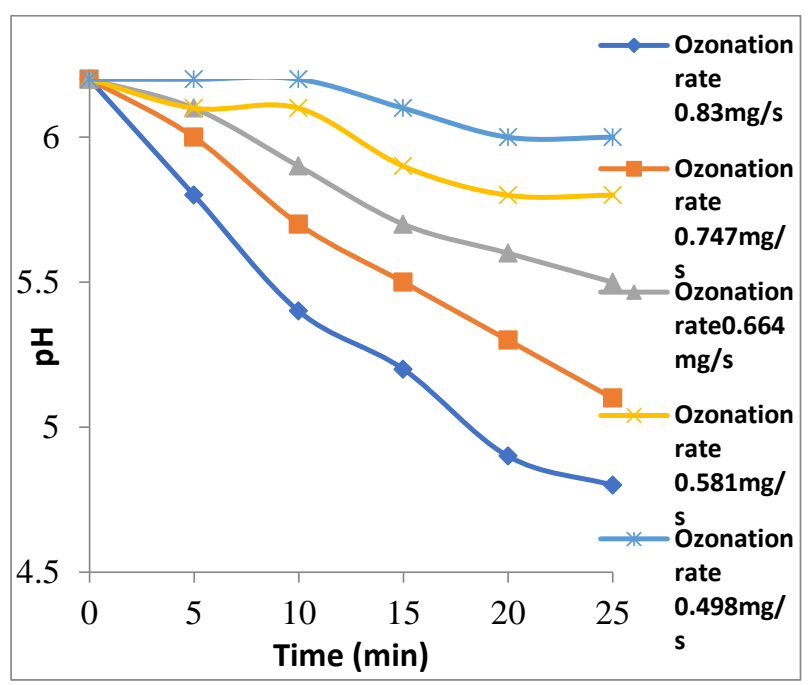

Figure 11: Variation of $\mathrm{pH}$ with Ozonation rate at different time intervals $(\mathrm{MB}$ concentration $=15 \mathrm{mg} / \mathrm{l}, \mathrm{pH}=$ 6.2). 


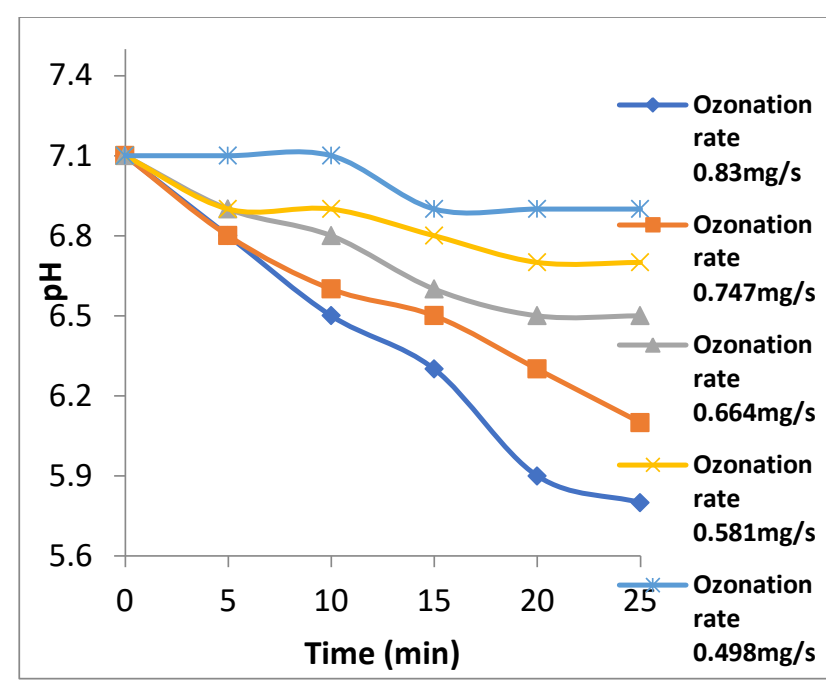

Figure 12: Variation of $\mathrm{pH}$ with Ozonation rate at different time intervals (MB concentration $=15 \mathrm{mg} / \mathrm{l}, \mathrm{pH}=$ 7.1).

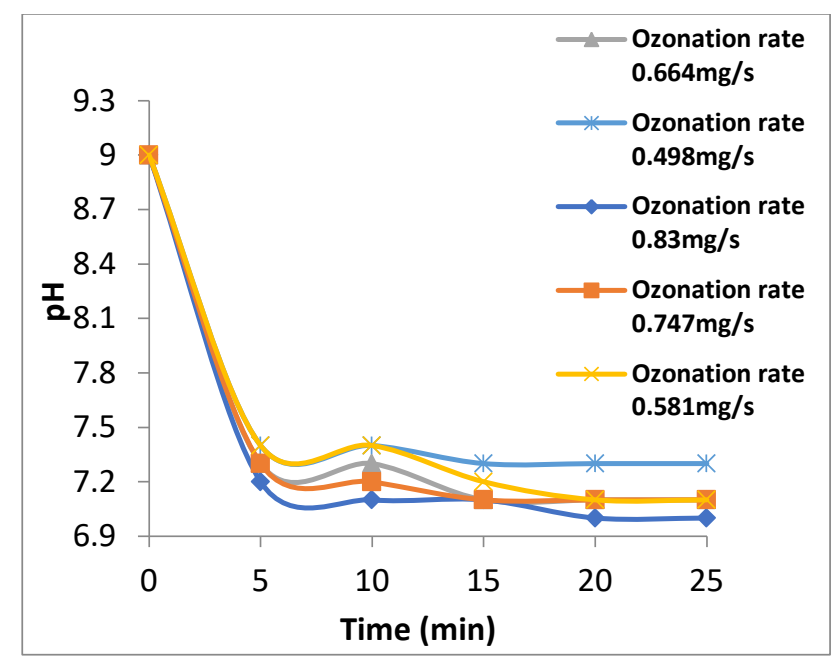

Figure 13: Variation of $\mathrm{pH}$ with Ozonation rate at different time intervals $(\mathrm{MB}$ concentration $=15 \mathrm{mg} / 1, \mathrm{pH}=$ 9).

From Figures [9-13], its clearly observed that when the Ozonation rate decrease the drop in the $\mathrm{pH}$ solution also decreased until the lowest Ozonation rate nearly remain constant ,and that because when the ozone concentration is low that enhancing the indirect reaction when hydroxyl radical is produced in addition to strong acids that resulting from Ozonation process so that the $\mathrm{pH}$ of the solution remain approximately constant or unchange at this stage $[3,6]$

\subsection{Self-decomposition rate constant of ozone}

\subsubsection{Evaluation of ozone self-decomposition rate constant}

Ozone mass transfer in the aqueous phase for nonreacting systems by micro bubbles had been reported previously in the literature by Khuntia et al; (2013) [17] In this study, the ozone self-decomposition rate constant be determined through kinetic studies on our semi - batch reactor. The dissolved ozone concentration in water has been calculated as a function of time and continue until it was reached saturation, which referred to the ozone concentration steady state, $\left[C_{A L}\right]$ ss. After that, the generation of ozone was stopped and the reduce in the ozone concentration in the reactor was determined during the experiment time as shown in Fig. 11. The time taken to achieve steady state ozone concentration decreased when the $\mathrm{pH}$ of the medium increased. Ozone decomposition in water depends on the $\mathrm{pH}$ and it was followed a pseudo first-order kinetics and that reported in in Khuntia et al., (2013) [17]; Sotelo et al., (1989) [26]; and Sotelo et al., (1987) [27]. The self-decomposition reaction rate of ozone equation can be

$-\frac{d\left[C_{A L}\right]}{d t}=k_{d}\left[C_{A L}\right]$

Where $\left[C_{A L}\right]$ is the ozone concentration in the aqueous solution and $\mathrm{kd}$ is the rate constant of ozone selfdecomposition. Equation (8) integrated with the boundary condition that at $\mathrm{t}=0,\left[C_{A L}\right]=\left[C_{A L}\right]$ ss and this gives the following equation:

$\ln \frac{\left[C_{A L}\right]_{S S}}{\left[C_{A L}\right]}=k_{d} t$

Eq. (9) predicts that kd would be the slope of a straight line passing through the origin and this line is a plot of $1 n$ $\left[C_{A L}\right] \mathrm{ss} /\left[C_{A L}\right]$ versus time $\mathrm{t}$, , Table 1 summarizes the experimental values of $\mathrm{kd}$ at various $\mathrm{pH}$.

Table .1: The experimental values of $\mathrm{kd}$ at different $\mathrm{pH}$.

\begin{tabular}{|c|c|c|c|}
\hline $\mathrm{pH}$ & 5 & 7 & 9 \\
\hline $\boldsymbol{k}_{\boldsymbol{d}}\left(\boldsymbol{m} \boldsymbol{s}^{-\mathbf{1}}\right)$ & 0.039 & 0.03 & 0.025 \\
\hline
\end{tabular}

$\mathrm{kd}$ is a basic kinetic parameter, and it should be independent on the reactor type. On the other hand, the values investigated in the literature $[27,10,19,15]$ show extensive differences from one experiment to another. For example, kd values of $0.04 \mathrm{~m} / \mathrm{s}$ at $\mathrm{pH} 7$ was found by ( Gao M-T et al ., 2005)[10], kd values of 0.21-0.42 /s at pH 2.5-9 was measured by ( Sotelo et al ., 1987)[27], $0.21-0.54 \mathrm{~m} / \mathrm{s}$ at $\mathrm{pH} 2.6-7$ by ( Hsu et al ., 2002)[15], and $0.42 \mathrm{~m} / \mathrm{s}$ (pH unspecified) by (Kukuzaki et al ., 2010)[19] .The values of $\mathrm{kd}$ found in this study are similar to these values. 


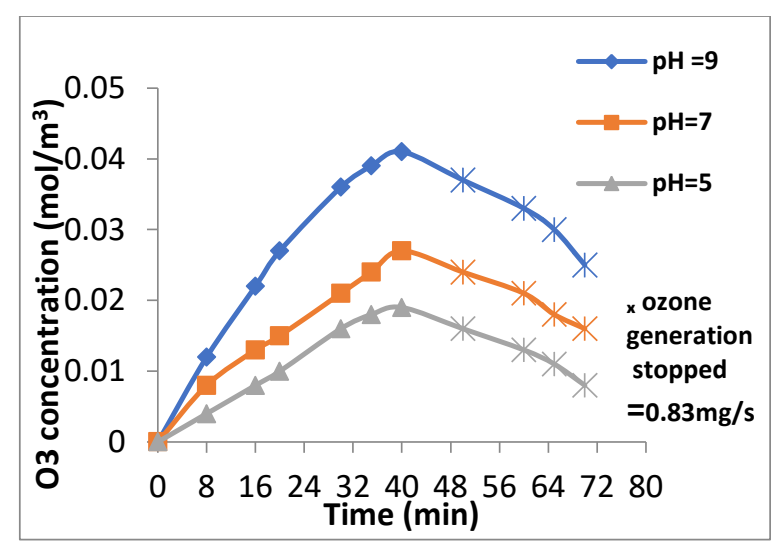

Figure 14: Concentration profiles of ozone during its self-decomposition when the ozone generation was stopped.

One of the parameters that have a significant effect on ozone decay is $\mathrm{pH}$. So as to be aware of the influence of $\mathrm{pH}$ on ozone decay, a number of experiments were conducted at various $\mathrm{pH}$ values of 5, 7, and 9. Figure 12 illustrated the $\mathrm{pH}$ effect on the decay rate of ozone when the experiments were carried out in the absence of any dye. It was observed that at low $\mathrm{pH}$ the decay rate of is slow and it was increases when the $\mathrm{pH}$ increased. Moreover, that's means; the half-life time $t_{1 / 2}$ of ozone was $\mathrm{pH}$ dependent, for that reason, any increase in the $\mathrm{pH}$ leads to a decrease in the $t_{1 / 2}$.

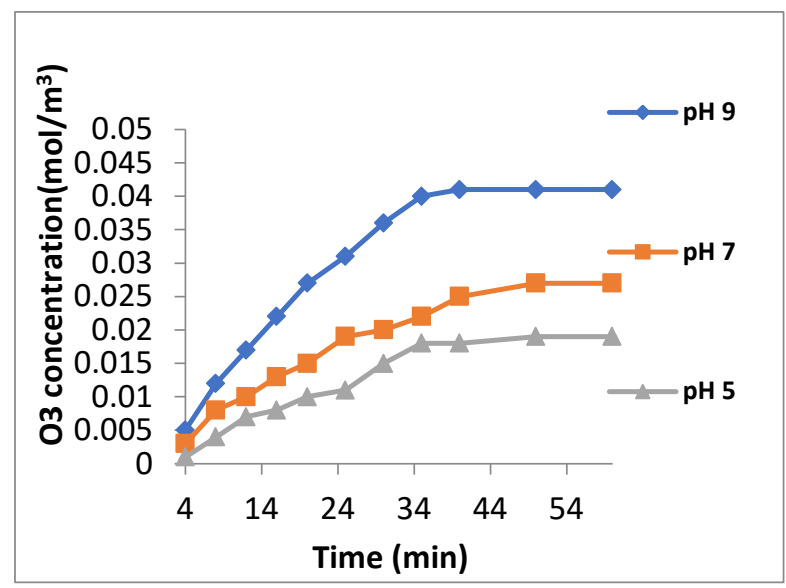

Figure 15: Dissolved ozone concentration in water at different $\mathrm{pH}$.

\subsection{Determination of volumetric mass transfer coefficient $\boldsymbol{k}_{L a}$ :}

As stated before, the absorption of ozone start to increase gradually with time until it reaches to the saturation value $C_{A L}^{*}$. The results in Figure 15 reveal that after $30 \mathrm{~min}$ at any $\mathrm{pH}$ value, the equilibrium concentration of ozone was reached. The saturation concentration of the ozone was $(0.04,0.025$ and 0.018$) \mathrm{mol} / \mathrm{m}^{3}$ at $\mathrm{pH}$ of 9,7 and 5 respectively.

The kinetic calculation will be performed at various $\mathrm{pH}$ values to investigate the influence of $\mathrm{pH}$ on the volumetric mass transfer coefficient for absorption process.

- For $\mathrm{pH}=$ 9: $\mathrm{K}=0.081259 \mathrm{~ms}^{-1}$ and $k_{L a}=0.056259 \mathrm{~ms}^{-1}$. Figure $\mathbf{. 1 6}$ show the experimental and the theoretical data that obtained from equation 10 [13]:

$C_{A L}=\frac{k_{l a}}{K} C_{A L}^{*}(1-\exp (-K t))$

Where: $\left(K=k_{L a}+k_{d}\right), k_{d}$ was determined from a separate experimental study as shown in Figure $14 ; C_{A L}^{*}$ was determined from the Figure 15.

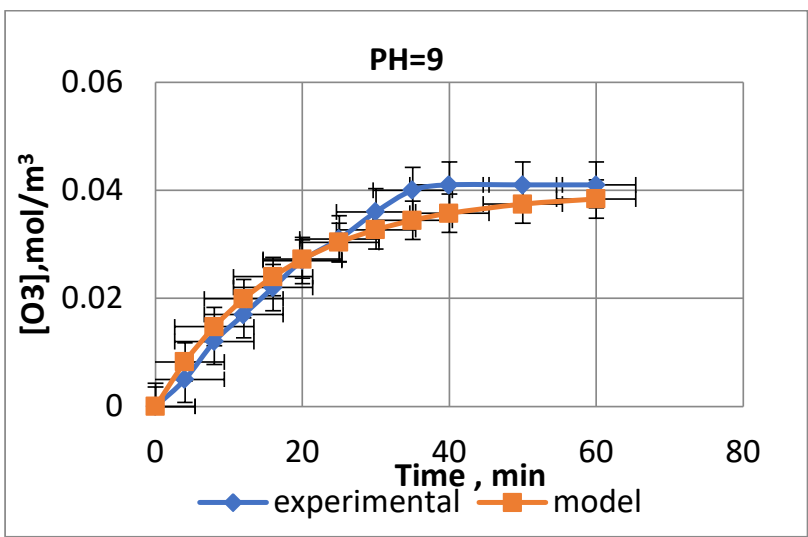

Figure 16: The experimental and theoretical data at $\mathrm{pH}=9$.

For $\mathrm{pH}=7: \quad \mathrm{K}=0.080366 \mathrm{~ms}^{-1}$ and $k_{L a}=0.050366 \mathrm{~ms}^{-1}$. Figure 17 shows the experimental and theoretical data.

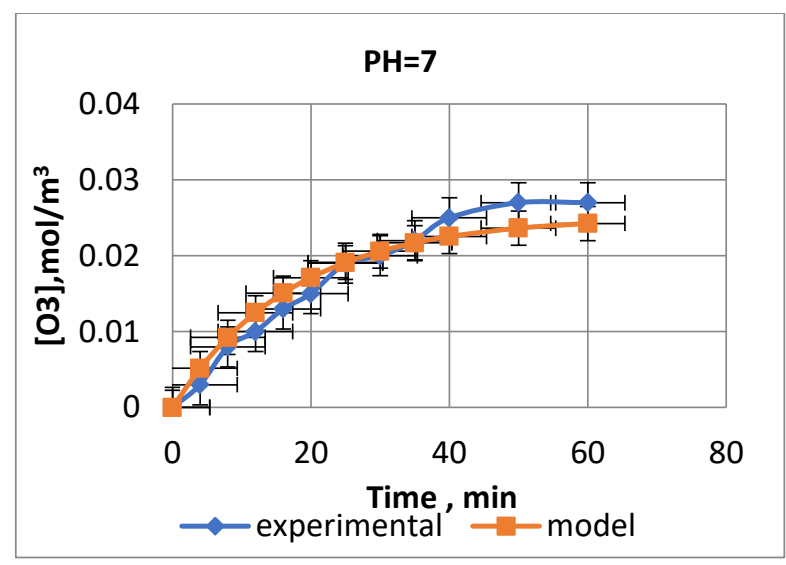

Figure 17: The experimental and theoretical data at $\mathrm{pH}=7$.

For $\mathrm{pH}=5: \mathrm{K}=0.0912 \mathrm{~ms}^{-1}$ and $k_{L a}=0.0522 \mathrm{~ms}^{-1}$. Figure 18 show the experimental and theoretical data for this case. 


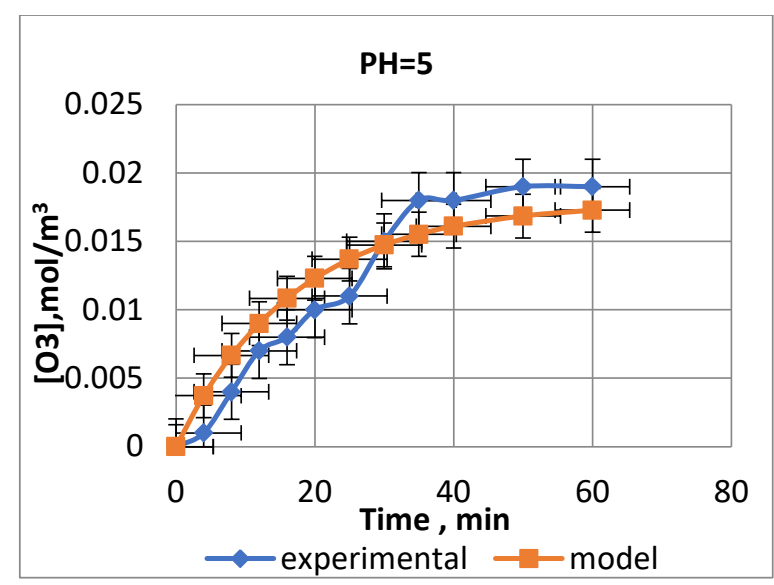

Figure 18: The experimental and theoretical data at $\mathrm{pH}=5$.

The results in Table (2) show the effect of $\mathrm{pH}$ on the constant rate of ozone absorption. When the $\mathrm{pH}$ increases to 9 , the constant rate of absorption also increases. $\mathrm{pH}$ was take place as a vital parameter in ozone reaction pathway. Molecular ozone oxidation have a tendency to dominate in an acidic conditions whereas, free-radical oxidation is dominated at higher $\mathrm{pH}$. This owes to the generation of hydroxyl radicals is improved in an alkaline condition. So, these radicals have an oxidation potential further more than ozone molecular [14], then the removal efficiencies of MB are expected to increase as alkalinity increases.

Table 2: The volumetric mass transfer at different $\mathrm{pH}$ and ozonation rate of $0.83 \mathrm{mg} / \mathrm{s}$ :

\begin{tabular}{|c|c|c|c|}
\hline $\mathrm{pH}$ & 5 & 7 & 9 \\
\hline $\boldsymbol{k}_{\boldsymbol{L} \boldsymbol{a}}, \boldsymbol{m s}^{\mathbf{- 1}}$ & 0.0522 & 0.050366 & 0.056259 \\
\hline
\end{tabular}

\subsection{Removal of chemical oxygen demand (COD) from MB aqueous solution}

In general, several organic chemicals such as dyes, biocides, ionic and non-ionic surfactants, carriers, sizing agents are contained in industrial wastewaters. As a result, it was difficult to establish the degradation rate for each organic compound present in wastewater individually. Hence, some worldwide waste water parameters such as COD were used as an indication for the degradation kinetics of organic compounds by Ozonation. For this purpose, experiments were carried out in order to assess the effect of ozonation process on the COD removal efficiency.

Figure 19 indicates the change of $\mathrm{COD}$ values of $\mathrm{MB}$ model solution with concentration of $100 \mathrm{mg} / \mathrm{l}$ after treatment with ozone microbubbles. As can be seen from the results, the color removal rate was increased with time. Within the first thirty minutes of the experiment, the color removal rate was around $45 \%$. Between 30 and 60 min, these rate of removal continued to increase rapidly, however, after $60 \mathrm{~min}$ a slowdown has been noticed.

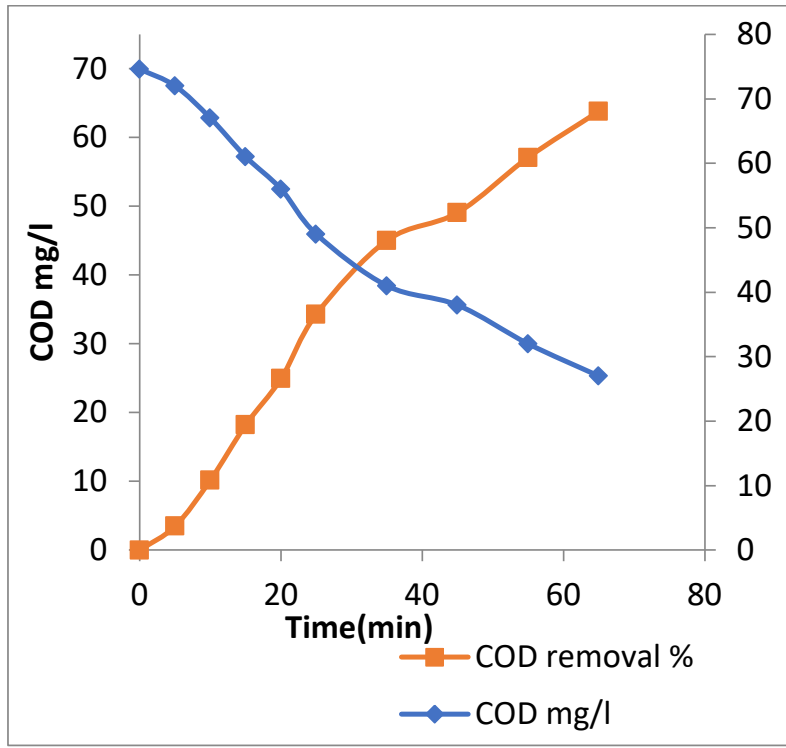

Figure 19: Removal of COD in $\mathrm{MB}$ aqueous solution $(\mathrm{MB}=100 \mathrm{mg} / \mathrm{l}, \mathrm{pH}=3.7$, at room temperature).

The decrease in the COD concentration of $\mathrm{MB}$ aqueous solution might be caused by the decomposition of MB by Ozonation which leads in turn to the formation of sulfoxides $(\mathrm{S}=\mathrm{O})$ in high yield. JAVIER et al., (1993)[8] found that 1 mole of ozone is required in this step. Moreover, another molecule of ozone can react with the $\mathrm{N}$ atom to give a hydroxylamine derivative which can be attacked later by a second molecule of ozone to yield a nitro compound [8].

\section{Conclusions}

This study was focused on investigating the efficiency of using ozone microbubbles for the oxidation of methylene blue dye (MB) from aqueous solutions. The data obtained from this work showed that this technique was very effective in removing MB from liquid medium. From the experimental work, it was found that acidic condition enhances the separation efficiency of MB. Removal efficiencies of about $98 \%$ was obtained under conditions of $\mathrm{pH} 3.7$ and ozone generation rate of $0.83 \mathrm{mg} / \mathrm{s}$. it was found that the direct reaction of $\mathrm{MB}$ with molecular ozone was the dominant during the separation process, while the reaction between MB and hydroxyl radical was inactive and it cannot degrade more than $20 \%$ of the dye at alkaline condition. It was also found that increasing the ozone generation rate, increases the concentration of dissolved ozone in the aqueous phase, which enhanced the degradation of $\mathrm{MB}$ at $\mathrm{pH}$ 3.7. Complete mineralization was accomplished at low $\mathrm{pH} 3.7$ and 0.83 $\mathrm{mg} \mathrm{s}^{-1}$ ozone generation rate. The COD removal rate for wastewater with $\mathrm{MB}$ initial concentration of $100 \mathrm{ppm}$ was approximately $64 \%$ after $65 \mathrm{~min}$ of treatment. Also, the oxidation of MB with ozone followed second-order rate constant. 


\section{References}

[1] Beltran, F.J., 2004. Ozone Reaction Kinetics for Water and Wastewater Systems. Lewis Publishers, Boca Raton.

[2] Carmen, Z., \& Daniel, S. (2012). Textile Organic Dyes - Characteristics, Polluting Effects and Separation/Elimination Procedures from Industrial Effluents - A Critical Overview. Organic Pollutants Ten Years After the Stockholm Convention Environmental and Analytical Update. doi:10.5772/32373.

[3] Chen, L.C. Effects of factors and interacted factors on the optimal decolorization process of methyl orange by ozone. Water Res. 2000, 34, 974-982. [CrossRef]

[4] Chu W. and Chi-Wai M. (1999). Quantitative prediction of direct and indirect dye ozonation kinetics. Water Res. 34 (12), 3153-3160.

[5] Chu, L.-B., Xing, X.-H., Yu, A.-F., Zhou, Y.-N., Sun, X.-L., Jurcik, B., 2007. Enhanced ozonation of simulated dyestuff wastewater by microbubbles. Chemosphere $68 \quad(10), \quad 1854 \mathrm{e} 1860$. http://dx.doi.org/10.1016/j.chemosphere.2007.03.0 14

[6] Constapel, M.; Schellenträger, M.; Marzinkowski, J.M.; Gäb, S. Degradation of reactive dyes in wastewater from the textile industry by ozone: Analysis of the products by accurate masses. Water. Res. 2009, 43, 733-743. [CrossRef] [PubMed]

[7] Dutta K, Mukhopadhyay S, Bhattacharjee S and Chaudhuri B 2001 Chemical oxidation of methylene blue using Fenton-like reactions J. Hazard. Mater. 84 57.

[8] F. JAVIER BENITEZ , JESUS BELTRANHEREDIA , TERESA GONZALEZ \& ANGELA PASCUAL (1993): OZONE TREATMENT OF METHYLENE BLUE IN AQUEOUS SOLUTIONS, Chemical Engineering Communications, 119:1, 151165.

[9] F.Banat, S. Al.-Asheh, M. Al.-Rawashdeh, M. Nusair, "Photodegradation of methylene blue dye by $\mathrm{UV} / \mathrm{H} 2 \mathrm{O} 2$ and UV/acetone oxidation processes", Desalination, 181(2005)225.

[10] Gao M-T, Hirata M, Takanashi H, et al. Ozone mass transfer in a new gas-liquid contactor - Karman contactor. Sep Purif Technol. 2005;42:145-149.

[11] Gottschalk, C., Libra, J.A., Saupe, A., 2010. Ozonation of Water and Waste Water: a Practical Guide to Understanding Ozone and its Applications. Wiley-VCH, Weinheim.
[12] Grabowski, L. R., Veldhuizen, E. M. van, Pemen, A. J. M., \& Rutgers, W. R. (2007). Breakdown of methylene blue and methyl orange by pulsed corona discharge. Plasma Sources Science and Technology, 16(2), 226-232. doi:10.1088/0963-0252/16/2/003.

[13] Grima, N. (2009). Kinetic and mass transfer studies of ozone degradation of organics in liquid/gas-ozone and liquid/solid-ozone systems., School of Engineering \&Technology, University of Bradford,UK.

[14] Hoigne, J., Bader, H., 1983. Rate constants of reactions of ozone with organic and inorganic compounds in watereI: non-dissociating organic compounds. Water Res. 17 (2), $173 \mathrm{e} 183$. http://dx.doi.org/10.1016/0043-1354(83)90098-2.

[15] Hsu Y-C, Chen T-Y, Chen J-H, et al. Ozone transfer into water in a gas-inducing reactor. Ind Eng Chem Res. 2002;41:120-127.

[16] Jabesa, A., \& Ghosh, P. (2016). Removal of diethyl phthalate from water by ozone microbubbles in a pilot plant. Journal of Environmental Management, 180, 476-484.doi:10.1016/j.jenvman.2016.05.072.

[17] Khuntia S, Majumder SK, Ghosh P. Removal of ammonia from water by ozone microbubbles. Ind Eng Chem Res. 2013;52:318-326.

[18] Khuntia, S., Majumder, S.K., Ghosh, P., 2015. Quantitative prediction of generation of hydroxyl radicals from ozone microbubbles. Chem. Eng. Res. Des. 98, 231e239. http://dx.doi.org/10.1016/j.cherd.2015.04.003.

[19] Kukuzaki M, Fujimoto K, Kai S, et al. Ozone mass transfer in an ozone-water contacting process with Shirasu porous glass (SPG) membranes - a comparative study of hydrophilic and hydrophobic membranes. Sep Purif Technol. 2010;72:347-356.

[20] Oliver J. Hao , Hyunook Kim \& Pen-Chi Chiang (2000) Decolorization of Wastewater, Critical Reviews in Environmental Science and Technology, 30:4, 449-505, DOI: 10.1080/1064338009118423.

[21] Oturan, M.A.; Aaron, J.J. Advanced oxidation processes in water/wastewater treatment: Principles and applications. A review. Crit. Rev. Env. Sci. Technol. 2014, 44, 2577-2641.

[22] Park J.S., Choi H., Cho J. (2004). Kinetic decomposition of ozone and parachlorobenzoic acid (p-CBA) during catalytic ozonation. Water Res. 38(9), 2285-2292.

[23] Ramakrishna, K. R., \& Viraraghavan, T. (1997). Dye removal using low cost adsorbents. Water Science and Technology, 36(2-3), 189196.doi:10.2166/wst.1997.0516. 
[24] Salem, I. A., \& El-Maazawi, M. S. (2000). Kinetics and mechanism of color removal of methylene blue with hydrogen peroxide catalyzed by some supported alumina surfaces. Chemosphere, 41(8), 11731180. doi:10.1016/s0045-6535(00)00009-6.

[25] Soares G.P., Saloma O., Orfao J.J.M., Portela D., Vieira A., Pereira M.R., (2006), Ozonation of Textile Effluents and Dye Solutions under Continuous Operation: Influence of Operating Parameters. J. Hazard. Mater. B137, 1664- 1673.

[26] Sotelo JL, Beltrán FJ, Benitez FJ, et al. Henry’s law constant for the ozone-water system. Water Res. 1989;23:1239- 1246.
[27] Sotelo JL, Beltran FJ, Benitez FJ, et al. Ozone decomposition in water: kinetic study. Ind Eng Chem Res. 1987;26:39-43.

[28] Staehelin, J. and Hoigne, J. (1985). Decomposition of Ozone in Water in the Presence of Organic Solutes Acting as Promoters and Inhibitors of Radical Chain Reactions. Environ. Sci. Technol., 19(12), 1206-1213.

[29]Xia, Z., \& Hu, L. (2018). Treatment of Organics Contaminated Wastewater by Ozone Micro-NanoBubbles. Water, 11(1), 55.doi:10.3390/w11010055.

[30] Yurteri, C., and Gürol, M.D. (1988). Ozone Consumption in Natural Waters: Effects of Background Organic Matter, $\mathrm{pH}$ and Carbonate Species. Ozone Sci. Eng., 10, 272- 282.

\section{ازالة صبغة المثيلين الزرقاء من المحلول المائي بواسطة فقاعات الاوزون الصغيرة}

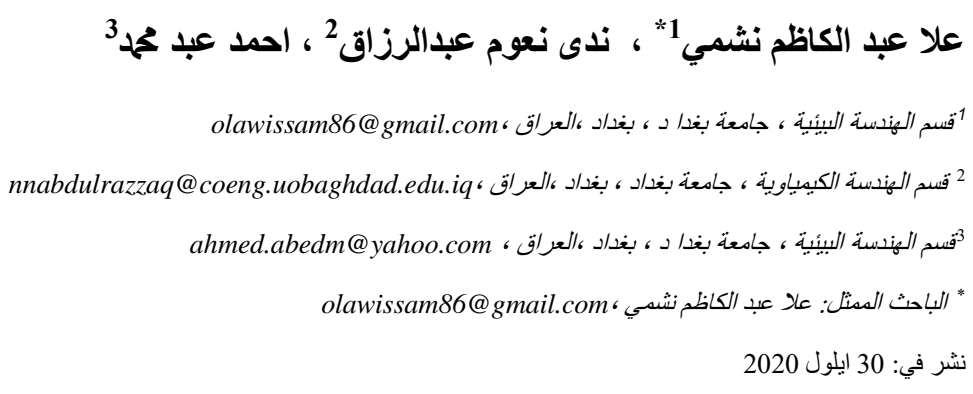

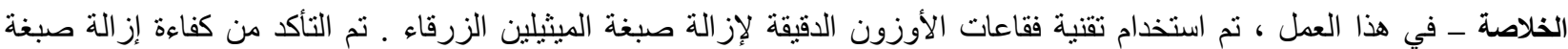

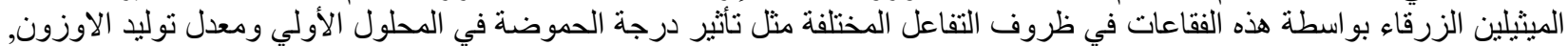

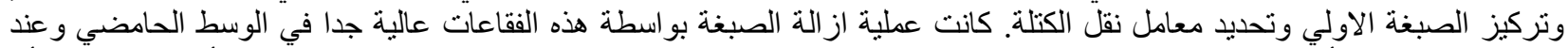

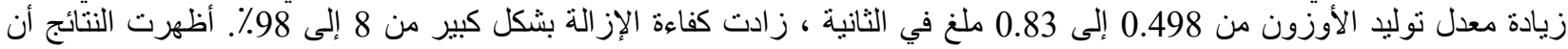
استخدام تقنية فقاعات الاوزون الوزون من الصغيرة فعالة جدا في از الة هذه الصبغة كليا. الكلمات الرئيسية ــ المثيلين الزرقاء، فقاعات الاوزون ، معدل الاز الة. 